Int. J. Electrochem. Sci., 14 (2019) 10340 - 10351

International Journal of

ELECTROCHEMICAL

SCIENCE

www.electrochemsci.org

\title{
Nitrogen doped Carbon Nanotubes as Electrocatalyst for Oxygen Reduction Reaction
}

\author{
Utsav Raj Dotel ${ }^{1}$, Fatemeh Davodi ${ }^{2}$, Olli Sorsa ${ }^{2}$, Tanja Kallio ${ }^{2}$, Tor Hemmingsen ${ }^{1, *}$ \\ ${ }^{1}$ Department of Natural Science and Mathematics, University of Stavanger, NO-4036 Stavanger, \\ Norway \\ ${ }^{2}$ Department of Chemistry and Material Science, Aalto University, Kemistintie 1 D 102150 Espoo, \\ Finland \\ *E-mail: tor.hemmingsen@uis.no
}

doi: $10.20964 / 2019.11 .06$

Received: 25 February 2019/ Accepted: 15 July 2019 / Published: 7 October 2019

The oxygen reduction reaction on nitrogen doped multiwalled carbon nanotubes (N-MCNTs) is studied for its application for deoxygenation of seawater. N-MCNTs were synthesized using commercial MCNTs and polyaniline as nitrogen precursor and annealing at a high temperature. The ORR was studied on N-MCNTs in $0.5 \mathrm{M}$ sodium chloride solution using a rotating disk electrode, and physical characterization of the electrocatalysts was performed using X-ray diffraction, mass spectroscopy and transmission electron microscope techniques. The material showed high activity for the ORR in the chloride electrolyte. The onset potential for N-MCNTs was $0.94 \mathrm{~V}$ vs RHE. Koutecky-Levich analysis showed that the electrons transfer mainly followed the four-electron pathway, and the electrocatalyst showed good stability during a 15 -h stability test.

Keywords: Seawater, Deoxygenation, Oxygen reduction, Carbon nanotubes.

\section{$\underline{\text { FULL TEXT }}$}

(C) 2019 The Authors. Published by ESG (www.electrochemsci.org). This article is an open access article distributed under the terms and conditions of the Creative Commons Attribution license (http://creativecommons.org/licenses/by/4.0/). 